\title{
The brave new world of medicine by testimonial
}

$\mathrm{W}$ e've heard a lot of health care punditry lately stressing that Canada's health care system needs to be more patientcentred, which is great in theory, but what does that actually look like on the ground? Some have said that one manifestation would be to have more patient input in policy decisions and there are some signs governments are taking that notion seriously.

The British Columbia Ministry of Health has launched a website inviting patient input into the decision-making process at BC's new Drug Benefit Council, an advisory board that decides which drugs the province will cover.

The government press release noted that $\mathrm{BC}$ is the "only jurisdiction in Canada to accept input into drug review decisions from individual patients and caregivers." What it doesn't state is that this move also satisfied a demand from the pharmaceutical industry, which has long pressured the $\mathrm{BC}$ government to open up its drug review processes. The Better Pharmacare Coalition, a collection of patient disease groups, almost all which take funding from industry, was first in line registering as the voice of $\mathrm{BC}$ patients.

This is one example of a larger movement worldwide as the pharmaceutical industry strives to influence health decision-making bodies. By getting patients to represent a pharma-friendly face in health policy arenas, and having real patients personalize the disease and its treatment as well as supply compelling personal stories, the companies can make regulators more sympathetic to approving or funding their drugs.

In November, a US Food and Drug Administration (FDA) committee reviewed a new drug, Benlysta (belimumab), for the treatment of lupus. Among the patients and groups who gave testimonials at the meeting was Karen Britt of Jackson, Tennessee. ${ }^{1}$ She told the committee the experimental drug had given her a new life and the mostly bedridden woman said she hoped she'd soon be dancing at her wedding. She also told a journalist that Human Genome Sciences, Benlysta's maker, helped fund her travel to the committee meeting.

And what does the science say about this new treatment that may replace current therapies for lupus? There were only two trials and data from them raise some red flags, including one strange

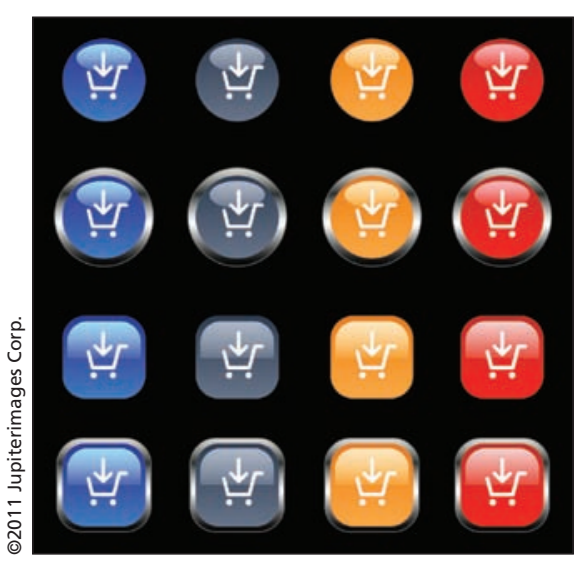

fact that the drug showed no benefit in North American patients. It was only marginally effective in patients in the overseas trial where 1 in 11 patients might see some benefit. ${ }^{2}$ The FDA committee heard that the new treatment was also associated with slightly more deaths and suicides compared to placebo. Its expected price tag? About $\$ 30000$ per patient annually.

Whether or not the cost is worth the benefit is one question. The bigger question this FDA review process and the new approval process in $\mathrm{BC}$ raises is this: How appropriate it is to have patients weigh into drug approval decision-making committees armed with little but personal testimonials?

Here's a thought experiment: If I were wealthy and felt it was important to fund patients to show up at drug review committees to voice their opinions of the drug in question, what is stopping me from finding patients whose lives were made worse by the drug, who suffered a serious adverse event or almost died? What if I paid them or the family members of patients who died in the drug's trials to present testimonials to the committee, making the point that, for some people, the drug may be nasty, worthless or even dangerous? Would that be fair?

I think you get my point. We can invite as many patient testimonials as possible to participate in drug policy decision-making, but what will actually happen on the ground? More one-sided anecdotes to obscure an already cloudy picture? That's what I am afraid of.

The bottom line is the simple fact that the plural of anecdote is not data. A pile of stories do not create trustworthy clinical evidence on which to build drug policy decisions. And we shouldn't act like they do.

As my provincial government brags about its fair and unbiased drug review process, we've got groups like BC's Better Pharmacare Coalition ready to weigh into the fray, funded by the very drug companies who support them. What is their ammunition? Favourable testimonials.

Will those testimonials influence decisions? It might be too early to tell. However, the FDA committee voted 13 to 2 in favour of approving Benlysta, and while the FDA will make its final decision in March, typically it follows committee recommendations.

A sad day for all of us, but another victory in the Brave New World of medicine by testimonial.

\section{Alan Cassels MPA \\ Drug policy researcher \\ University of Victoria \\ Victoria, BC}

\section{References}

1. Pollack A. F.D.A. Panel backs drug for lupus. The New York Times. 2010 Nov.16. Available: www.nytimes.com/2010/11/17/health/17drug.html (accessed 2011 Jan. 13)

2. US Food and Drug Administration. Arthritis Drugs Advisory Committee: Drugs briefing package. 16 Nov.2010. Silver Spring (MD): The Administration; 2010. Available: www.fda.gov/downloads /AdvisoryCommittees/CommitteesMeetingMaterials /Drugs/ArthritisDrugsAdvisoryCommittee/ UCM233579.pdf (accessed 2011 Jan. 13)

CMAJ 2011. DOI:10.1503/cmaj.101889 